\title{
Effect of 2-hydroxy-4-(methylthio)butanoate (HMTBa) on risk of biohydrogenation-induced milk fat depression
}

\author{
M. Baldin, ${ }^{* 1}$ G. I. Zanton, $\dagger^{2}$ and K. J. Harvatine ${ }^{\star^{3}}$ \\ *Department of Animal Science, The Pennsylvania State University, University Park 16802 \\ †Novus International Inc., St. Charles, MO 63304
}

\begin{abstract}
Diet-induced milk fat depression (MFD) is a multifactorial condition resulting from the interaction of numerous risk factors, including diet fermentability and unsaturated fatty acids concentration, feed additives, and individual cow effects. 2-Hydroxy-4-(methylthio) butanoate (HMTBa) is a methionine analog that has been observed to increase milk fat in some cases, and interactions with MFD risk factors may exist. The objective was to evaluate the effect of HMTBa supplementation on milk fat synthesis in cows with different levels of milk production and fed diets with increasing risk of biohydrogenation-induced MFD. Sixteen highproducing cows $(44.1 \pm 4.5 \mathrm{~kg}$ of milk $/ \mathrm{d}$; mean $\pm \mathrm{SD})$ and 14 low-producing $(31.4 \pm 4.3 \mathrm{~kg}$ of milk/d) were used in a randomized block design. Treatments were unsupplemented control and HMTBa fed at $0.1 \%$ of diet dry matter $(25 \mathrm{~g} / \mathrm{d}$ at $25 \mathrm{~kg}$ of dry matter intake). The experiment was $70 \mathrm{~d}$ and included a 14 -d covariate period followed by 3 phases whereby diets were fed with increasing risk of MFD to determine the interaction of treatment and diet-induced MFD. During the lowrisk phase, the base diet was balanced to $33.5 \%$ neutral detergent fiber (NDF) and had no exogenous oil (28 d); during the moderate-risk phase, the diet was balanced to $31 \% \mathrm{NDF}$ and contained $0.75 \%$ soybean oil $(14 \mathrm{~d})$; and, during the high-risk phase, the diet was balanced to $28.5 \%$ NDF and contained 1.5\% soybean oil (14 d). An interaction of treatment, production-level, and dietary phase was observed. Low producing cows neither experienced substantial biohydrogenation-induced MFD nor a response in milk fat to HMTBa supplementation. In high-producing cows, HMTBa maintained higher milk fat concentration during the moderate- (2.94 vs. 3.49\%) and high-risk (2.38 vs. $3.11 \%$ ) phases. High-producing
\end{abstract}

\footnotetext{
Received July 5, 2017.

Accepted September 19, 2017.

${ }^{1}$ Current address: Provimi North America, 10 Nutrition Way, Brookville, OH 45309.

${ }^{2}$ Current address: USDA-Agricultural Research Service, U. S. Dairy Forage Research Center, Madison, WI 53706.

${ }^{3}$ Corresponding author: kjh182@psu.edu
}

cows receiving HMTBa also had greater milk fat yield (0.94 vs. $1.16 \mathrm{~kg} / \mathrm{d}$ ) and lower trans-10 C18:1 (6.11 vs. 1.50) during the high-risk phase. In conclusion, HMTBa increased milk fat in situations with a high risk of biohydrogenation-induced MFD by decreasing absorption of alternate biohydrogenation intermediates.

Key words: 2-hydroxy-4-(methylthio)butanoate, biohydrogenation, milk fat, milk fat depression

\section{INTRODUCTION}

Fat is one of the most important components of milk, as it significantly affects the value of milk, the yield and quality of dairy products, and because of the recent associations between consumption of milk bioactive fatty acids (FA) and human health (Bainbridge et al., 2016). Consequently, the mechanisms regulating milk fat synthesis in the mammary gland, as well as nutritional and management strategies that improve milk fat synthesis, have been studied extensively. Low-milk fat syndrome, contemporarily called diet-induced milk fat depression (MFD), is a condition in which milk fat yield decreases up to $50 \%$ with generally no change in yields of milk and other milk components (Harvatine et al., 2009b). Milk fat synthesis is affected by several factors (e.g., genetics, physiological state, and environment), but is especially responsive to nutrition. The biohydrogenation (BH) theory (Bauman and Griinari, 2003) of MFD is a unifying concept that mechanistically explains the inhibition of milk fat synthesis when feeding highly fermentable and high-UFA diets. This model attributes the causal mechanism to changes in ruminal $\mathrm{BH}$ pathways, leading to increased formation and rumen outflow of specific bioactive FA that inhibit mammary lipid synthesis.

The understanding of dietary regulation of milk fat synthesis has improved, yet varying levels of MFD still commonly occur on dairy farms. This is primarily because MFD is a multifactorial condition resulting from the interaction of several factors, such as dietary FA level, FA profile and availability, diet fermentability, feeding strategies, rumen modifiers, and individual cow effects (Harvatine, 2017). Diet UFA level and 
carbohydrate fermentability have been characterized as central risk factors for BH-induced MFD (Rico and Harvatine, 2013; Rico et al., 2014a). Additionally, an association between level of milk production and risk of BH-induced MFD has been proposed. For instance, supplementation with calcium salts of UFA decreased milk fat in high-producing cows, whereas no MFD was observed in the low-producing cows (Harvatine and Allen, 2006; Rico et al., 2014b).

Varying levels of evidence support the effectiveness of some rumen modifiers in attenuating BH-induced MFD. Early work observed that the methionine analog, 2-hydroxy-4-(methylthio)butanoate (HMTBa), increased milk fat when feeding highly fermentable diets (Rosser et al., 1971; Huber et al., 1984). A recent meta-analysis observed increased milk fat yield with HMTBa supplementation (Zanton et al., 2014), but it was inconclusive on the role of HMTBa in circumstances of MFD. As BH-induced MFD is the result of the interaction of numerous factors, studying one single factor at a time will be less informative and more inconsistent than studying multiple factors simultaneously. The current study was conducted to evaluate the interaction between dietary risk factors (UFA and carbohydrate fermentability), cow milk production level, and supplementation with a rumen modifier (HMTBa). The objective was to evaluate the effect of HMTBa supplementation on milk fat synthesis in 2 groups of cows with different levels of milk production and fed diets with increasing risk of BH-induced MFD. Our hypothesis was that high-producing cows are at higher risk of BH-induced MFD and that HMTBa would reduce the extent of BH-induced MFD.

\section{MATERIALS AND METHODS}

\section{Experimental Design and Treatments}

All experimental procedures were approved by the Pennsylvania State University Institutional Animal Care and Use Committee. The experiment was conducted from October to December 2013 at the Pennsylvania State University Dairy Production Research and Teaching Center (University Park). Thirty multiparous Holstein cows were used in a randomized block design that tested the effect of treatment during 3 dietary phases that progressively increased risk for diet-induced MFD. Animals were housed individually in tiestalls with rubber mattresses and sawdust bedding and had continuous access to water. Cows were blocked by milk production (high or low) at the end of a 14-d pretrial period (Table 1). The high-producing group (n $=16 ; 166 \pm 69 \mathrm{~d}$ postpartum; mean $\pm \mathrm{SD}$ ) averaged $44.1 \pm 4.5 \mathrm{~kg} / \mathrm{d}$ of milk and the low-producing group $(\mathrm{n}=14 ; 267 \pm 82 \mathrm{~d}$ postpartum) averaged $31.4 \pm 4.3$ $\mathrm{kg} / \mathrm{d}$ of milk. Cows were paired within block (high and low) and randomly assigned to 1 of the 2 treatments: control $(\mathbf{C O N})$ or HMTBa $(0.1 \%$ of diet DM, targeting $25 \mathrm{~g}$ of HMTBa per cow/d at $25 \mathrm{~kg}$ of DMI; Table 2). The HMTBa (Alimet, Novus International Inc., St. Charles, MO) was provided in a corn carrier and mixed in the TMR. An equivalent amount of the same ground corn carrier was added to the control treatment. The experiment was split into 3 phases that fed diets formulated to have low, moderate, and high risk of BH-induced MFD, respectively (Table 3). Risk for altered $\mathrm{BH}$ was increased by reducing diet NDF and increasing UFA and starch content (Table 3). Diet UFA were increased using a combination of rapidly available FA from soybean oil and more slowly available FA from roasted soybeans. The low-risk phase was $28 \mathrm{~d}$ to allow complete adaptation of the rumen to HMTBa, and the moderate- and high-risk phases were $14 \mathrm{~d}$, as previous time course work has demonstrated that changes in $\mathrm{BH}$ occur within 10 to $14 \mathrm{~d}$ (Rico and Harvatine, 2013). Importantly, phase is the repeated variable and the effect of treatment is only compared within phase, as phase and treatment are confounded. Diets were fed as a TMR once daily at $0700 \mathrm{~h}$ at $110 \%$ of expected daily intake. Cows were treated with rbST (Posilac, Elanco Animal Health, Greenfield, IN) every 14 d.

\section{Sampling and Measurements}

Feed intake was measured daily. Cows were milked twice daily at 0500 and $1700 \mathrm{~h}$ and milk yield determined by an integrated milk meter (AfiMilk, SAE Afikim, Afikim, Israel). The parlor was calibrated using a stall deviation calculated using data from the entire herd (>200 cows) over $7 \mathrm{~d}$. Stall deviations were determined by modeling the effect of day, milking (a.m./p.m.), cow, and stall, excluding observations of experimental cows during treatment periods. Milk was sampled at both milkings once per week and was composited based on yield at each milking. Body weight was recorded as cows exited the parlor throughout the trial (AfiFarm 3.04E scale system, SAE Afikim). Feed ingredients were sampled once per week and stored at $-20^{\circ} \mathrm{C}$, thawed at room temperature, dried at $55^{\circ} \mathrm{C}$ in a forced-air oven for $72 \mathrm{~h}$, and ground in a Wiley mill through a 1-mm screen (A. H. Thomas, Philadelphia, PA). Feed samples were composited within dietary phase (equal dry weight basis). Blood samples were collected from the tail vein using potassium EDTA vacuum tubes (Greiner Bio-One North America Inc., Monroe, NC) at 0600, 1400, and $2000 \mathrm{~h}$. Blood was immediately placed on ice, centrifuged within $30 \mathrm{~min}$ at $1,300 \times g$ for $15 \mathrm{~min}$ at $4^{\circ} \mathrm{C}$, and plasma was harvested 
Table 1. Characteristics of cows in the low- and high-production block at the end of the pretrial period

\begin{tabular}{|c|c|c|c|c|}
\hline \multirow[b]{2}{*}{ Item } & \multicolumn{2}{|c|}{ Block $^{1}$} & \multirow[b]{2}{*}{ SEM } & \multirow[b]{2}{*}{$P$-value } \\
\hline & Low & High & & \\
\hline DIM & 267 & 166 & 19.4 & $<0.01$ \\
\hline DMI (kg/d) & 24.7 & 26.8 & 0.62 & 0.02 \\
\hline Milk yield (kg/d) & 31.4 & 44.1 & 1.30 & $<0.001$ \\
\hline Milk fat $(\%)$ & 3.94 & 3.20 & 0.16 & $<0.01$ \\
\hline Milk fat (kg/d) & 1.12 & 1.37 & 0.06 & 0.01 \\
\hline Milk protein (\%) & 3.40 & 3.26 & 0.08 & 0.22 \\
\hline Milk protein $(\mathrm{kg} / \mathrm{d})$ & 0.97 & 1.40 & 0.04 & $<0.001$ \\
\hline \multicolumn{5}{|l|}{ Milk FA, $\mathrm{g} / 100 \mathrm{~g}$ of total $\mathrm{FA}^{2}$} \\
\hline trans-10 C18:1 & 0.48 & 0.77 & 0.12 & 0.11 \\
\hline$\Sigma<16 \mathrm{C}$ & 25.4 & 25.8 & 0.62 & 0.57 \\
\hline$\Sigma 16 \mathrm{C}$ & 25.9 & 26.9 & 0.52 & 0.20 \\
\hline$\Sigma>16 \mathrm{C}$ & 41.1 & 39.2 & 0.83 & 0.13 \\
\hline
\end{tabular}

and stored at $-20^{\circ} \mathrm{C}$ until laboratory analysis. Prior to analysis, plasma samples from 1400 and $2000 \mathrm{~h}$ were composited by cow to represent a postabsorptive state.

\section{Sample Analysis}

Feed samples were analyzed for DM, CP, and starch by wet chemistry procedures according to AOAC International (2000) and for NDF and ADF according to Van Soest et al. (1991). Total FA concentration and FA profile of feed samples was determined by GC after direct methylation (Sukhija and Palmquist, 1988), as described by Rico and Harvatine (2013). Plasma samples were analyzed for insulin (Coat-a-count insulin kit, Siemens Healthcare Diagnostics, Los Angeles, CA), glucose (PGO Enzyme procedure no. P 7119, SigmaAldrich, St. Louis, MO), BUN [Modified Enzymatic Urea Nitrogen (Procedure No. 2050); Stanbio Laboratory, Boerne, TX], and FA (Wako HR Series NEFA-HR kit, Wako Chemicals USA Inc., Richmond, VA), as modified by Ballou et al. (2009).

One milk sample was stored at $4^{\circ} \mathrm{C}$ with preservative (Bronolab-WII, Advanced Instruments Inc.,
Norwood, MA) until analyzed for fat and protein by Fourier transform infrared spectroscopy (Fossomatic 4000 Milko-Scan and 400 Fossomatic, Foss Electric, Hillerød, Denmark; at Dairy One Laboratory, Ithaca, NY). A second milk sample was immediately centrifuged at $3,000 \times g$ for $15 \mathrm{~min}$ at $4^{\circ} \mathrm{C}$ and fat cake was stored at $-20^{\circ} \mathrm{C}$ before analysis of FA composition, as described by Rico and Harvatine (2013). In short, lipid extraction was performed according to Hara and Radin (1978) using hexane:isopropanol. Fatty acid methyl esters were prepared by base-catalyzed transmethylation according to Chouinard et al. (1999). Fatty acid methyl esters were quantified by GC using an Agilent 6890A gas chromatograph (Agilent Technologies, Palo Alto, CA) equipped with a fused-silica capillary column (SP$2560,100 \mathrm{~m} \times 0.25 \mathrm{~mm}$ i.d. with $0.2-\mu \mathrm{m}$ film thickness; Supelco Inc., Bellefonte, PA) and a flame ionization detector with hydrogen as the carrier gas. Initial oven temperature was $80^{\circ} \mathrm{C}$, which was increased by $2^{\circ} \mathrm{C} / \mathrm{min}$ to $190^{\circ} \mathrm{C}$ and held for $15 \mathrm{~min}$. Inlet and detector temperatures were $250^{\circ} \mathrm{C}$ with a $100: 1$ split ratio. Constant gas flows were $1 \mathrm{~mL} / \mathrm{min}$ for hydrogen carrier, $25 \mathrm{~mL} /$ min for detector hydrogen, $400 \mathrm{~mL} / \mathrm{min}$ for detector

Table 2. Overview of experimental design

\begin{tabular}{|c|c|c|c|c|}
\hline \multirow[b]{2}{*}{ Item } & & \multicolumn{3}{|c|}{ BH-induced MFD risk ${ }^{1}$} \\
\hline & & $\begin{array}{l}\text { Low, } \\
\text { d } 0 \text { to } 28\end{array}$ & $\begin{array}{l}\text { Moderate, } \\
\text { d } 29 \text { to } 42\end{array}$ & $\begin{array}{l}\text { High, } \\
\text { d } 43 \text { to } 56\end{array}$ \\
\hline Block $^{2}$ & High & $\begin{array}{l}\text { Control } \\
\text { HMTBa }^{3} \\
\text { Control } \\
\text { HMTBa }\end{array}$ & $\begin{array}{l}\text { Control } \\
\text { HMTBa } \\
\text { Control } \\
\text { HMTBa }\end{array}$ & $\begin{array}{l}\text { Control } \\
\text { HMTBa } \\
\text { Control } \\
\text { HMTBa }\end{array}$ \\
\hline
\end{tabular}

${ }^{1}$ Risk of biohydrogenation (BH)-induced milk fat depression (MFD).

${ }^{2}$ Milk production level: low-producing cows (low) averaged $31.4 \pm 4.3 \mathrm{~kg} / \mathrm{d}$ and high-producing cows (high) averaged $44.1 \pm 4.5 \mathrm{~kg} / \mathrm{d}$ at the end of the pretrial period.

${ }^{3} \mathrm{HMTBa}=2$-hydroxy-4-(methylthio) butanoate. 
airflow, and $40 \mathrm{~mL} / \mathrm{min}$ for detector nitrogen plus carrier. Fatty acid peaks were identified using FAME standards (GLC 461, GLC 780, and pure trans-10,cis-12 CLA and cis-9,trans-11 CLA, NuChek Prep Inc., Elysian, MN; Bacterial Acid Methyl Ester Mix, 47080-U, Sigma-Aldrich; and GLC 110 mixture, Matreya LLC., State College, PA). Recovery of individual FA were determined using an equal weight reference standard (GLC 461; NuChek Prep Inc.). Correction factors for individual FA and calculation of milk FA yield were carried out as described by Rico and Harvatine (2013).

\section{Statistical Analysis}

Data were analyzed as a randomized block design using PROC MIXED of SAS with repeated measures (version 9.3; SAS Institute Inc., Cary, NC). An interaction of treatment, production level (block), and experimental day (dietary phase) was observed; thus, data were analyzed within block (high or low) with the following reduced model

$$
\mathrm{Y}_{\mathrm{ijkl}}=\mu+\mathrm{T}_{\mathrm{i}}+\mathrm{C}_{\mathrm{j}}\left(\mathrm{T}_{\mathrm{i}}\right)+\mathrm{D}_{\mathrm{k}}+\mathrm{T}_{\mathrm{i}} \mathrm{D}_{\mathrm{k}}+\beta_{1}+\varepsilon_{\mathrm{ijkl}},
$$

where $Y_{\mathrm{ijk}}$ is the variable of interest, $\mu$ is the overall mean, $T_{i}$ is the fixed effect of treatment (control or HMTBa), $\mathrm{C}_{\mathrm{j}}\left(\mathrm{T}_{\mathrm{i}}\right)$ is the random effect of cow nested within treatment $\mathrm{i}, \mathrm{D}_{\mathrm{k}}$ is the fixed effect of experimental day $(k=1$ to 8$), T_{i} D_{k}$ is the interaction of treatment and experimental day, $\beta_{1}$ is the fixed effects of pretrial measurements (covariate), and $\varepsilon_{\mathrm{ijkl}}$ is the residual error. The $\mathrm{ARH}(1)$ or $\mathrm{AR}(1)$ covariance structures were used depending on model fit and the Kenward-Roger denominator degrees of freedom adjustment was employed. The preplanned contrast tested the effect of HMTBa at each day. In the time-course data, the treatment effect was similar within dietary phase (low, moderate, and high risk of MFD); therefore, for simplicity, effect of treatment was tested by 2 -wk intervals that matched dietary phases. Data points with Studentized residuals outside of \pm 3.0 were considered outliers and excluded from analysis, which typically included less than 4 data points per variable. Significant differences were

Table 3. Ingredient and chemical composition of basal diets with increasing risk of biohydrogenation (BH)induced milk fat depression (MFD)

\begin{tabular}{|c|c|c|c|}
\hline \multirow[b]{2}{*}{ Item } & \multicolumn{3}{|c|}{ Risk of BH-induced MFD } \\
\hline & Low & Moderate & High \\
\hline \multicolumn{4}{|l|}{ Ingredient ( $\%$ of DM) } \\
\hline Corn silage & 40.5 & 38.1 & 35.0 \\
\hline Alfalfa haylage & 14.7 & 13.6 & 12.5 \\
\hline Processed grass hay & 2.9 & 2.7 & 2.5 \\
\hline Ground corn & 7.7 & 12.3 & 17.2 \\
\hline Canola meal & 11.6 & 11.1 & 10.9 \\
\hline Cottonseed hulls & 4.1 & 3.5 & 2.8 \\
\hline Roasted soybeans ${ }^{1}$ & 3.5 & 5.6 & 6.6 \\
\hline Minerals and vitamins $\operatorname{mix}^{2}$ & 3.3 & 3.3 & 3.3 \\
\hline Soybean oil & 0.0 & 0.7 & 1.5 \\
\hline Corn gluten meal & 4.3 & 4.2 & 4.0 \\
\hline Soybean hulls & 5.0 & 2.5 & 1.4 \\
\hline Molasses & 2.5 & 2.4 & 2.3 \\
\hline \multicolumn{4}{|c|}{ Composition (\% of DM, unless noted) } \\
\hline $\mathrm{CP}$ & 17.1 & 17.3 & 17.3 \\
\hline $\mathrm{RDP}(\%$ of $\mathrm{CP})$ & 62.0 & 61.6 & 61.1 \\
\hline $\mathrm{ADF}$ & 23.5 & 21.2 & 19.3 \\
\hline NDF & 33.9 & 30.9 & 28.5 \\
\hline Forage NDF & 20.2 & 18.3 & 17.5 \\
\hline Starch & 24.4 & 26.8 & 29.2 \\
\hline Fatty acids & 4.1 & 4.9 & 5.6 \\
\hline PUFA & 2.2 & 2.7 & 3.1 \\
\hline MUFA & 0.9 & 1.1 & 1.2 \\
\hline peNDF $^{3}$ & 19.0 & 17.3 & 15.1 \\
\hline
\end{tabular}

${ }^{1}$ Whole soybeans were roasted in a mobile roaster and were approximately $158^{\circ} \mathrm{C}$ when removed from the roaster. Beans were rolled into approximately quarters before feeding.

${ }^{2}$ Composition (DM basis): $11 \%$ CP; $18 \%$ NDF; $5.2 \%$ fat; $14.9 \% \mathrm{Ca} ; 0.35 \% \mathrm{P} ; 4.58 \% \mathrm{Mg} ; 0.41 \% \mathrm{~K} ; 0.31 \% \mathrm{~S}$; $357 \mathrm{mg} / \mathrm{kg}$ of $\mathrm{Cu} ; 1,085 \mathrm{mg} / \mathrm{kg}$ of Zn; $181 \mathrm{mg} / \mathrm{kg}$ of Fe; $6.67 \mathrm{mg} / \mathrm{kg}$ of Se; 262,105 IU/kg of vitamin A; 65,421 $\mathrm{IU} / \mathrm{kg}$ of vitamin D; and 1,970 IU/kg of vitamin E (Cargill Animal Nutrition, Roaring Spring, PA).

${ }^{3}$ peNDF $=$ physically effective NDF. Analyzed using the Penn State Particle Separator (Nasco, Fort Atkinson, WI). Particles remaining (\% of total) in the upper sieve, middle sieve, lower sieve, and bottom pan were 3, 37, 16 , and 44 , respectively, for the low-risk diet; $3,35,18$, and 44 , respectively, for the moderate-risk diet; 3,35 , 15 , and 47 , respectively, for the high-risk diet. 
Table 4. Effect of 2-hydroxy-4-(methylthio)butanoate (HMTBa) on performance and milk composition in high- and low-producing cows

\begin{tabular}{|c|c|c|c|c|c|c|c|}
\hline Item $(\mathrm{kg} / \mathrm{d}$, unless noted $)$ & Block $^{1}$ & \multicolumn{2}{|c|}{ Treatment $(\text { Trt })^{2}$} & SEM & \multicolumn{3}{|c|}{$P$-value ${ }^{3}$} \\
\hline DMI & $\mathrm{H}$ & 27.3 & 25.6 & 0.74 & 0.10 & $<0.01$ & 0.53 \\
\hline \multirow[t]{2}{*}{ Milk yield } & $\mathrm{H}$ & 40.8 & 39.5 & 3.85 & 0.74 & 0.01 & 0.47 \\
\hline & $\mathrm{L}$ & 21.5 & 23.8 & 1.34 & 0.24 & $<0.01$ & 0.81 \\
\hline Milk fat (\%) & $\mathrm{H}$ & 2.98 & 3.42 & 0.10 & $<0.01$ & $<0.01$ & $<0.05$ \\
\hline Milk fat & $\mathrm{L}$ & 0.80 & 0.98 & 0.07 & 0.10 & $<0.01$ & 0.96 \\
\hline \multirow[t]{2}{*}{ Milk protein (\%) } & $\mathrm{H}$ & 3.33 & 3.36 & 0.08 & 0.46 & $<0.01$ & 0.64 \\
\hline & $\mathrm{L}$ & 3.63 & 3.52 & 0.07 & 0.05 & $<0.01$ & 0.58 \\
\hline \multirow[t]{2}{*}{ Milk protein } & $\mathrm{H}$ & 1.40 & 1.28 & 0.06 & 0.17 & 0.54 & 0.38 \\
\hline & $\mathrm{L}$ & 0.73 & 0.85 & 0.04 & 0.06 & $<0.01$ & 0.16 \\
\hline
\end{tabular}

${ }^{1}$ Milk production level: high-producing cows $(\mathrm{H})$ averaged $44.1 \pm 4.5 \mathrm{~kg} / \mathrm{d}$ and low-producing cows $(\mathrm{L})$ averaged $31.4 \pm 4.3 \mathrm{~kg} / \mathrm{d}$ at the end of the pretrial period.

${ }^{2}$ Treatment was control (ground corn) or HMTBa (0.1\% of diet DM provided in a ground corn carrier).

${ }^{3}$ Effect of treatment (Trt), experimental day, and their interaction.

declared at $P<0.05$ for main effects and $P<0.10$ for interactions and tendencies were declared at $P<0.10$ for main effects and $P<0.15$ for interactions.

\section{RESULTS}

\section{Effect of Production Level}

Milk yield and composition differed between the lowand high-producing blocks at the end of the pretrial period (Table 1). Low-producing cows had $95 \mathrm{~d}$ greater DIM, $2.1 \mathrm{~kg} / \mathrm{d}$ lower DMI, and $12.7 \mathrm{~kg} / \mathrm{d}$ lower milk yield compared with high-producing cows (Table 1). Additionally, low-producing cows had 0.74 percentage points higher milk fat concentration, but had lower yield of milk fat $(248 \mathrm{~g} / \mathrm{d} ; P=0.01)$ and milk protein $(427$ $\mathrm{g} / \mathrm{d} ; P<0.001)$. No difference between the 2 blocks was observed for FA by source (de novo, mixed source, and preformed), but trans-10 C18:1 was numerically higher in high-producing cows (0.77 vs. $0.48 ; P=0.11$; Table 1).

\section{Performance Responses}

Body weight was not affected by treatment and averaged $740 \pm 30 \mathrm{~kg}$ in the high-producing group and 703 $\pm 19 \mathrm{~kg}$ in the low-producing group $(P=0.90$ and $P=$ 0.70 , respectively). Dry matter intake, milk yield, and milk protein concentration and yield were not affected by treatment in either block (Table 4). Moreover, no treatment by day interaction was observed for any of these variables (Table 4). A tendency for higher milk protein concentration ( 3.63 vs. $3.52 \%, P=0.05$ ) in lowproducing cows in the control treatment was observed.
We found no effect of treatment or treatment by day interaction for milk fat concentration and yield in the low-producing group (Table 4). Milk fat concentration remained relatively constant and milk fat yield decreased slightly over the 3 dietary phases in low-producing cows on both treatments (Figure 1A and B). On the other hand, a treatment by day interaction was observed for milk fat concentration and yield in the high-producing group (Table 4). In the high-producing cows, milk fat concentration did not differ between treatments during the low-risk phase; but, during the moderate- and high-risk phases, control cows progressively decreased milk fat content, whereas HMTBa cows maintained higher milk fat concentration $(0.55$ and 0.73 percentage points, respectively; Figure 1A and Supplemental Table S1, https://doi.org/10.3168/ jds.2017-13446). Milk fat yield did not differ between treatments during low and moderate risk phases, but was higher by $220 \mathrm{~g} / \mathrm{d}$ in HMTBa during the high-risk phase (Supplemental Table S1 and Figure 1B).

No overall effect of treatment was observed on the concentration of BUN, nonesterified FA, glucose, and insulin in plasma of high- or low-producing cows in either fasting or postabsorptive state $(P>0.12$ for all; Supplemental Table S2, https://doi.org/10.3168/ jds.2017-13446). The treatment by time by production level interaction was not significant for the plasma variables $(P>0.50$ for all $)$.

\section{Milk FA}

We observed no overall effect of treatment or treatment by day interactions for trans-11 C18:1, trans-10 C18:1, FA by source (de novo, mixed, and preformed), 
and total odd- and branched-chain FA (OBCFA) in the low-producing block (Table 5). In the high-producing cows we found a treatment by day interactions for trans-11 C18:1, trans-10 C18:1, and sum of de novo synthesized FA ( $<16 \mathrm{C}$; Table 5$)$. During the highrisk phase, high-producing cows supplemented with HMTBa had $35.3 \%$ higher trans-11 C18:1, 2.3-fold lower trans-10 C18:1, and higher de novo FA $(<16 \mathrm{C})$ concentration in milk fat (Figures 2 and 3). Individual FA $<16$ carbons generally followed a similar pattern (Supplemental Tables S3, S4, and S5; https://doi.org/ 10.3168/jds.2017-13446). Although a treatment by

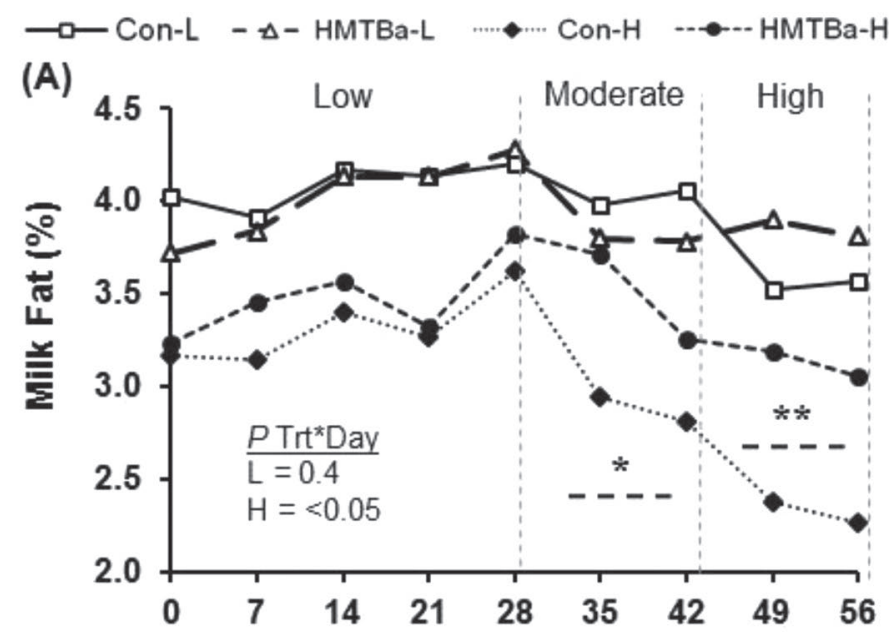

(B)

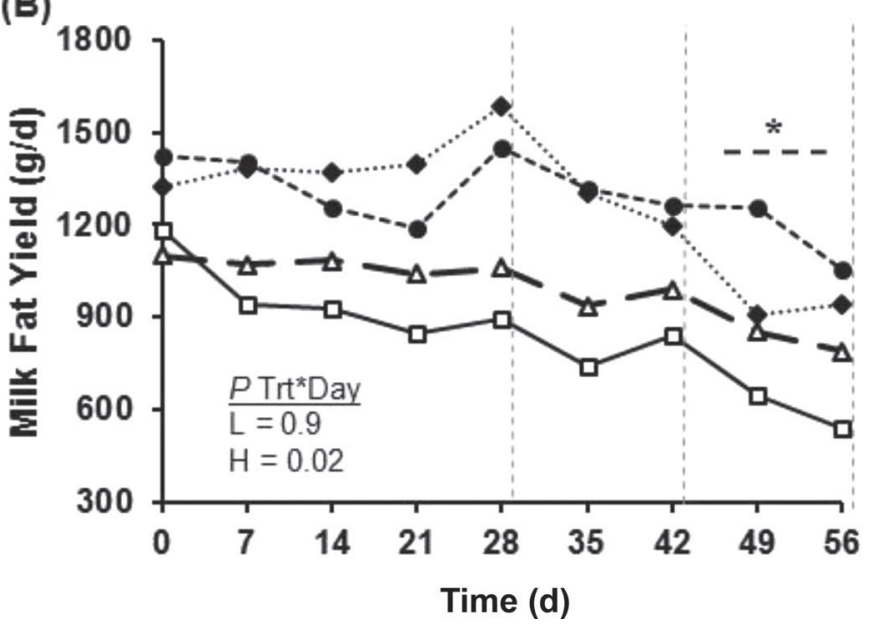

Figure 1. Effect of 2-hydroxy-4-(methylthio)butanoate (HMTBa) supplementation $(0.1 \%$ of $\mathrm{DM})$ on milk fat concentration $(\mathrm{A})$ and yield (B) in high- (Con-H and HMTBa-H) and low-producing (Con-L and HMTBa-L) cows receiving diets with low, moderate, and high risk for biohydrogenation-induced milk fat depression. High-producing cows averaged $44.1 \pm 4.5 \mathrm{~kg} / \mathrm{d}$ and low-producing cows averaged $31.4 \pm 4.3$ $\mathrm{kg} / \mathrm{d}$. Effect of treatment (control vs. HMTBa) within each dietary phase in high-producing cows is shown $\left({ }^{*} P<0.05\right.$ and $\left.{ }^{* *} P<0.01\right)$. Treatments (Trt) did not differ at any time point in low-producing cows $(P>0.05)$. Pooled SEM for milk fat concentration was 0.22 and 0.20 in low- and high-producing cows, respectively. Pooled SEM for fat yield was 0.12 and 0.09 in low-and high-producing cows, respectively. day interaction was not observed for OBCFA, in highproducing cows during the high-risk phase HMTBa increased C15:0 and C17:0 (Supplemental Figure S1, https://doi.org/10.3168/jds.2017-13446), and resulted in greater total OBCFA concentration (3.04 vs. 2.79 $\mathrm{g} / 100 \mathrm{~g}$ of total FA, $P=0.04$; Supplemental Table S2).

\section{DISCUSSION}

The sequentially increasing risk factor design allowed the efficient investigation of the interaction between HMTBa, susceptibility to MFD due to production level, and dietary challenge (low, moderate, and high risk for BH-induced MFD). Decreasing diet NDF and increasing starch and UFA is a well-characterized model to alter ruminal $\mathrm{BH}$ pathways and induce the formation of bioactive FA that inhibit milk fat synthesis (Bauman and Griinari, 2003; Rico and Harvatine, 2013; Rico et al., 2014a). Increasing starch concentration from 24.4 to 26.8 to $29.2 \%$ of the diet is expected to have decreased rumen $\mathrm{pH}$ and altered microbial populations to those adaptable to starch digestion and lower $\mathrm{pH}$, although neither were measured in the current experiment. The physically effective NDF during the moderate- and high-risk diets (17.3 and $15.1 \% \mathrm{DM}$, respectively) was below the suggested threshold of $21 \%$ required to maintain rumen $\mathrm{pH}$ below 6.0 (Zebeli et al., 2007). Of note, responses to HMTBa have been demonstrated to be independent of rumen pH (Vázquez-Añón et al., 2001; Lee et al., 2015). Increasing diet PUFA from 2.2 to 2.7 and $3.1 \%$ of the diet increased the amount of rumenavailable UFA requiring $\mathrm{BH}$ and is also expected to have modified the microbial population by selecting against populations sensitive to UFA.

Rico and Harvatine (2013) characterized the timecourse of BH-induced MFD and demonstrated that milk fat content and yield were decreased by d 3 and 5 , respectively, and the maximal response occurred in approximately 7 to $10 \mathrm{~d}$. Additionally, concentration of trans-10 C18:1 and trans-10,cis-12 CLA in milk fat increased progressively and were higher than control on $\mathrm{d} 1$ and 3, respectively. Changes in key microbial populations have also been demonstrated to occur over a similar rapid time-course during $\mathrm{BH}$-induced MFD (Rico et al., 2015). In summary, we highlighted the fast adaptation of rumen microbes to changes in diet fermentability and UFA and supported the use of 10- to 14-d experimental periods to investigate $\mathrm{BH}$-induced MFD.

Cows were grouped based on level of milk production, but DIM, DMI, and milk fat and protein concentrations and yields also differed between the blocks, as expected. A 3-way interaction of treatment, dietary risk, and production level for milk fat concentration 
BALDIN ET AL.

Table 5. Effect of 2-hydroxy-4-(methylthio)butanoate (HMTBa) on selected milk fatty acids (FA) in high- and low-producing cows

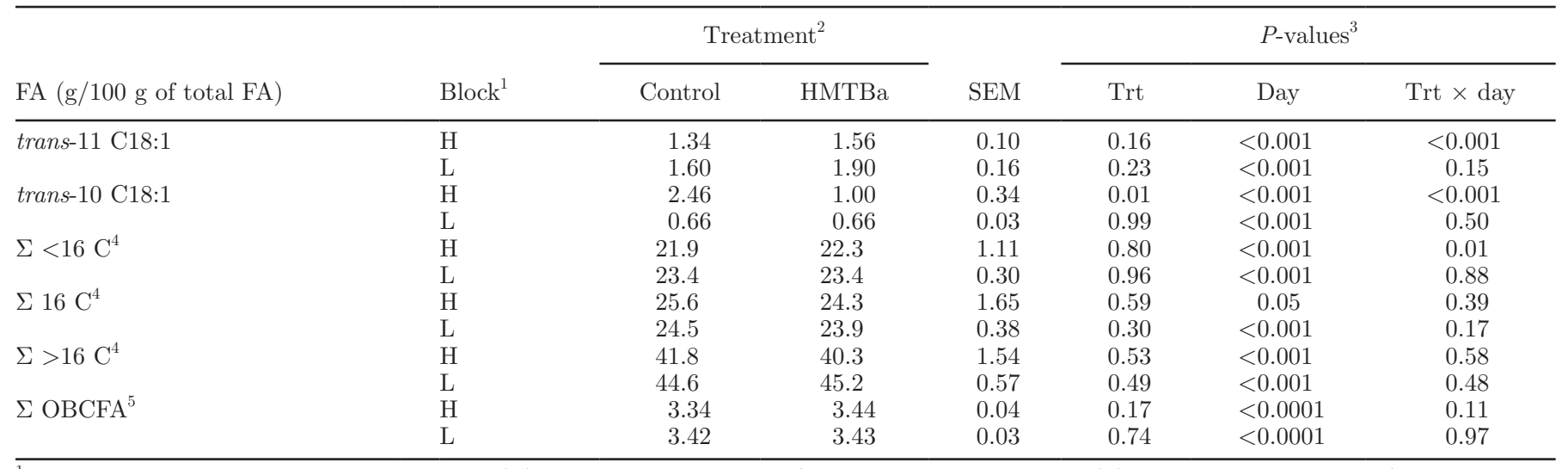

${ }^{1}$ Milk production level: high-producing cows $(\mathrm{H})$ averaged $44.1 \pm 4.5 \mathrm{~kg} / \mathrm{d}$ and low-producing cows $(\mathrm{L})$ averaged $31.4 \pm 4.3 \mathrm{~kg} / \mathrm{d}$ at the end of the pretrial period.

${ }^{2}$ Treatment was control (ground corn) or HMTBa ( $0.1 \%$ of diet DM provided in a corn carrier).

${ }^{3}$ Effect of treatment (Trt), experimental day, and their interaction.

${ }^{4} \mathrm{FA}<16 \mathrm{C}$ originate from de novo synthesis in the mammary gland, FA $>16 \mathrm{C}$ originate from extraction from plasma, and $16 \mathrm{C}$ FA originate from both sources.

${ }^{5}$ Sum of all odd- and branched-chain fatty acids in milk.

required the analysis within production blocks. Briefly, BH-induced MFD did not occur in low-producing cows, and the effects of HMTBa supplementation would have to occur through a different mechanism to affect milk fat production in this block. The low-producing group was composed primarily by late-lactation cows. Energy status of the cow may be a more important determinant of hormonal profile than stage of lactation (Peel et al., 1983), and cows in the high-producing group were mid-lactation and also expected to be in a positive energy balance. We did not observe any treatment by production level interaction for plasma variables. Therefore, the differential response of low- and highproducing cows to dietary BH-induced MFD risk factors and HMTBa supplementation in the current study was not expected to have been mediated by hormonal status. Furthermore, as reviewed by Harvatine et al. (2009a), trans-10,cis-12 CLA (a potent bioactive trans FA formed during altered ruminal $\mathrm{BH}$ ) reduces milk fat yield during all phases of the lactation cycle. This indicates that, in the current study, the absence of MFD in low-producing cows was not related to a lower responsiveness of the mammary gland to bioactive trans FA that inhibit milk fat synthesis and is likely due to a reduced flow of bioactive FA from the rumen.

The high-producing cows in the current experiment had higher DMI. Jenkins et al. (2008) proposed that the kinetics of ruminal passage of feed particles directly affects the rates of lipolysis and $\mathrm{BH}$. Rumen passage rate is expected to increase as DMI increases, which may modify the microbial population and increase ruminal outflow of trans intermediate FA before complete $\mathrm{BH}$ has occurred. Additionally, high-producing cows may differ in feeding and ruminating behavior (e.g., increased meal size, slug feeding), which may result in subclinical rumen acidosis and further alteration of normal microbial populations and BH pathways (Harvatine, 2017). Milk trans-10 C18:1, a proxy of altered ruminal $\mathrm{BH}$, was $38 \%$ higher in high-producing cows at the end of the pretrial period, indicating presence of the alternate ruminal $\mathrm{BH}$ pathway before initiation of the trial. Furthermore, it suggests that high-producing cows may be at higher risk of BH-induced MFD even under a low-risk diet, which has been reported in 2 other studies with similar high- and low-producing blocks (Harvatine and Allen, 2006; Rico et al., 2014b).

Increasing dietary risk factors resulted in pronounced $\mathrm{BH}$-induced MFD in high-producing cows in the control treatment, as evidenced by a 14 and $30 \%$ decrease in milk fat concentration during the moderate- and high-risk phases, respectively. The extent of MFD in the high-risk phase is within the range of 25 to $38 \%$ observed using similar changes in diet fermentability and UFA content (Peterson et al., 2003; Harvatine and Bauman, 2006; Rico and Harvatine, 2013). The phenotype of the response observed in the current experiment, including decreased milk fat with no changes in milk yield or yield of other components, is characteristic of classical BH-induced MFD (Harvatine et al., 2009b). This is further supported by the substantial 7.9-fold increase in trans-10 C18:1 in milk fat of high-producing cows in the control treatment. Trans-10 C18:1 is a major intermediate formed during altered BH (Jenkins et al., 2008), and the concentration of trans-10 C18:1 in milk can serve as a proxy to characterize the condition. This is mostly because absorbed FA are rapidly incor- 
porated into milk fat (Harvatine and Bauman, 2011) and because the majority $(>85 \%)$ of preformed milk FA come from absorption in cows in a positive energy balance (Palmquist and Mattos, 1978).

We observed a 3-way interaction of treatment, dietary phase, and production level, where HMTBa supplementation resulted in greater milk fat concentration during
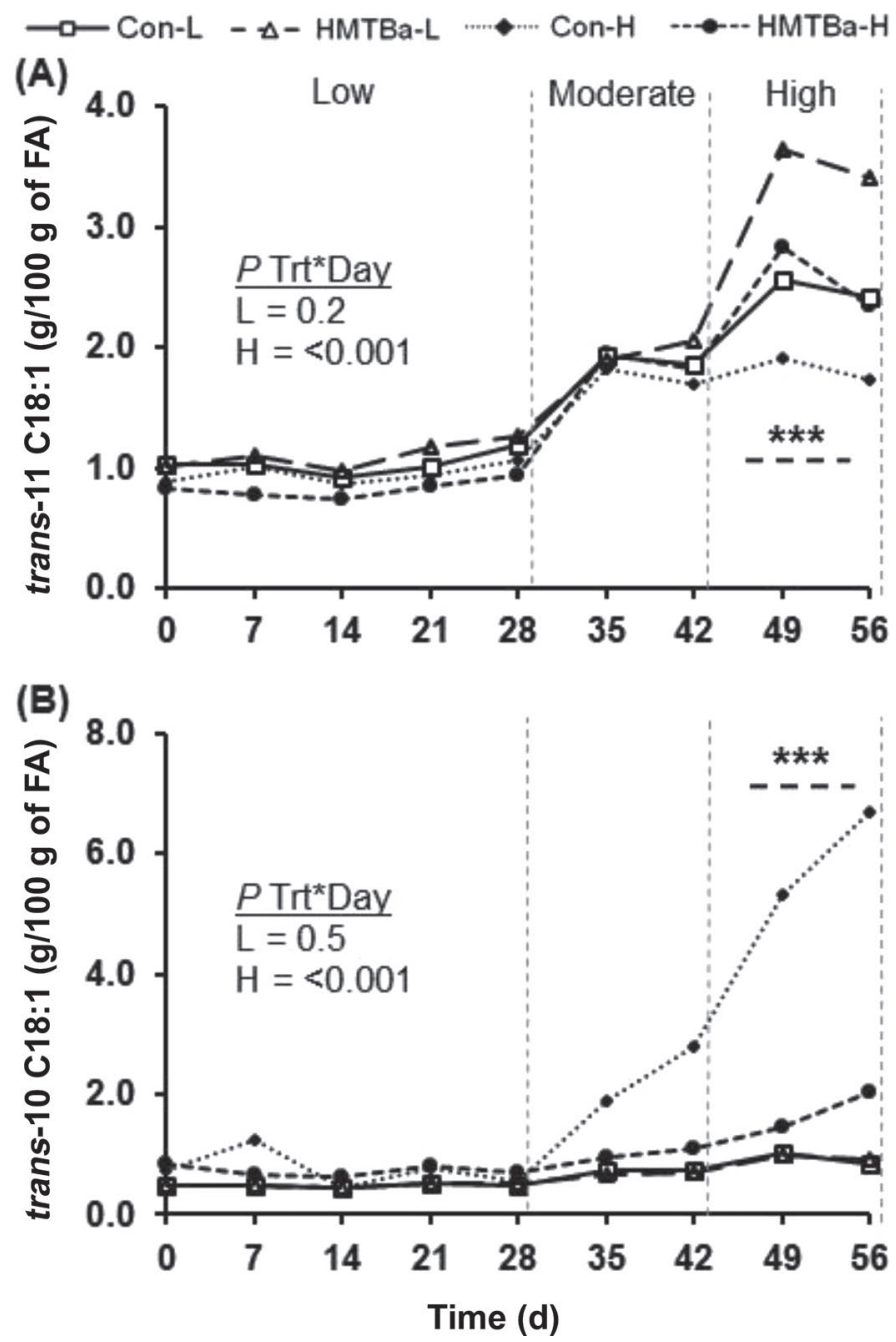

Figure 2. Effect of 2-hydroxy-4-(methylthio)butanoate (HMTBa) supplementation $(0.1 \% \mathrm{DM})$ on the milk fat concentration of the predominant isomers of the normal (trans-11 C18:1; A) and the alternate (trans-10 C18:1; B) biohydrogenation pathways in high- (Con- $\mathrm{H}$ and HMTBa-H) and low-producing (Con-L and HMTBa-L) cows receiving diets with low, moderate, and high risk for biohydrogenation-induced milk fat depression. High-producing cows averaged $44.1 \pm 4.5 \mathrm{~kg} / \mathrm{d}$ and low-producing cows averaged $31.4 \pm 4.3 \mathrm{~kg} / \mathrm{d}$. The treatment (Trt) by day interaction for high- $(\mathrm{H})$ and low-producing $(\mathrm{L})$ cows is shown. Significant differences between control and HMTBa in highproducing cows within each dietary phase are shown $(* * * P<0.01)$. Treatments did not differ $(P>0.05)$ at any time point in low-producing cows. Pooled SEM for trans-11 C18:1 was 0.40 and 0.20 in low- and high-producing cows, respectively. Pooled SEM for trans-10 C18:1 was 0.06 and 0.73 in low- and high-producing cows, respectively. $\mathrm{FA}=$ fatty acid

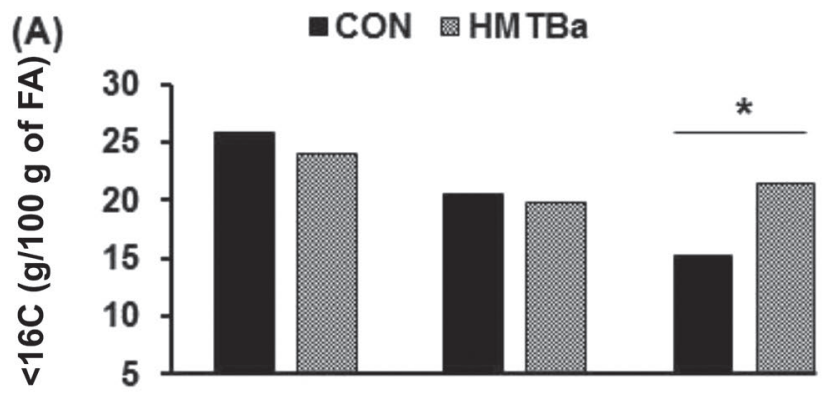

(B)
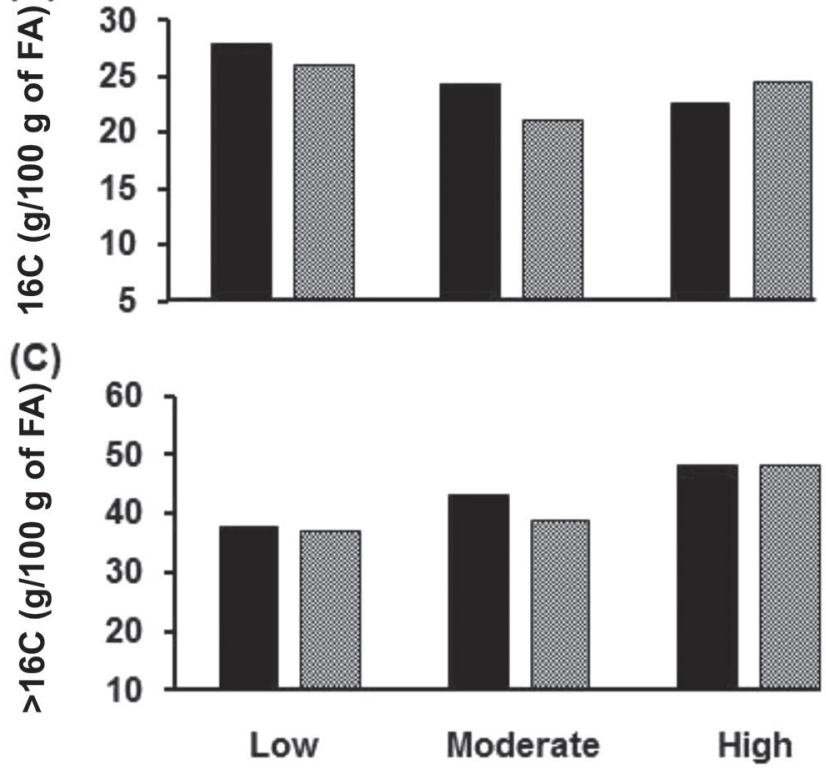

Figure 3. Effect of 2-hydroxy-4-(methylthio)butanoate (HMTBa) supplementation $(0.1 \%$ diet DM) on milk fatty acid (FA) concentration by source in high-producing cows $(44.1 \pm 4.5 \mathrm{~kg} / \mathrm{d})$ receiving diets with low, moderate, and high risk for biohydrogenation-induced milk fat depression. Fatty acids $<16 \mathrm{C}$ originate from de novo synthesis in the mammary gland (A), FA $>16 \mathrm{C}$ are extracted from plasma $(\mathrm{C})$, and 16-C FA from both sources $(B)$. Significance $\left({ }^{*} P<0.05\right)$ is presented for the control versus HMTBa within each dietary phase.

the moderate- and high-risk phases and greater milk fat yield in the high-risk phase in high-producing cows. Greater milk fat synthesis in HMTBa-supplemented high-producing cows resulted primarily from maintenance of the de novo FA synthesis pathway in the mammary gland. Supplementation with HMTBa, which is a hydroxyl analog of methionine, was initially intended to provide additional metabolizable methionine to the cow. However, with a reported ruminal degradability of $50 \%$ or more (Koenig et al., 1999; Noftsger et al., 2005), HMTBa may also affect rumen microbial composition or growth by providing methionine or through a rumen modifier mechanism. In fact, HMTBa has been suggested to increase bacterial $\mathrm{N}$ synthesis in vitro and in vivo, which could be associated with increased microbial protein yield (Vázquez-Añón et al., 2001; Lee et 
al., 2015). Early work proposed that the positive effect of HMTBa on milk fat was due to a direct effect of HMTBa on rumen lipid metabolism (Patton et al., 1970). However, the effect of HMTBa on milk fat is variable, but more apparent when feeding diets with increased risk of MFD. For example, Rosser et al. (1971) reported that supplementation with a methionine analog maintained milk fat synthesis when cows were fed a highly fermentable diet ( $85 \%$ pelleted concentrate). On the contrary, no increase in milk fat was observed when low-risk diets ( $>33 \% \mathrm{NDF}$ and $<3 \%$ ether extract) were supplemented with HMTBa (Johnson-VanWieringen et al., 2007; Lee et al., 2015).

In high-producing cows, HMTBa supplementation during the high-risk phase decreased the concentration of alternate $\mathrm{BH}$ isomers (trans-10 C18:1) and increased isomers of the normal pathway (trans-11 C18:1). This indicates a role for HMTBa in stabilizing rumen $\mathrm{BH}$ and reducing the shift to the altered trans-10 pathways that occurs during BH-induced MFD. This positive effect of HMTBa on ruminal $\mathrm{BH}$ could be mediated through 2 mechanisms. First, if an increase in microbial mass occurs with HMTBa supplementation (see discussion above), an increase in $\mathrm{BH}$ capacity would be expected. Second, HMTBa may modify the microbial population and maintain key ruminal microbial species important to BH. Rico et al. (2015) characterized the shift in common culturable microbial populations during BH-induced MFD and reported an increase in the abundance of Streptococcus bovis (amylolytic) and Megasphaera elsdenii and Selenomonas ruminantium (lactate-utilizing bacteria) and a decrease in Fibrobacter succinogenes (fibrolytic) and Butyrivibrio fibrisolvens/ Pseudobutyrivibrio group (BH-involved). Several studies have indicated that bacteria other than Butyrivibrio spp. might be involved in BH (Shingfield and Wallace, 2014), but the key populations in vivo are not clear. Additionally, Martin et al. (2013) observed an increase in the abundance of Fibrobacter succinogenes in rumen contents of cows supplemented with a methionine analog. Although F. succinogenes has been described primarily as fibrolytic, a role for this species in the $\mathrm{BH}$ of linoleic acid (C18:2) has also been proposed (Shingfield and Wallace, 2014). Baldin et al. (2015) evaluated the effect of HMTBa on microbial populations when feeding diets with increased risk of MFD. Even though there was an increase in the abundance of rumen protozoa, those authors reported no changes in 9 selected microbial taxa with well-characterized functions, including 2 species (Butyrivibrio/Pseudobutyrivibrio, Butyrivibrio hungatei) involved in trans-11 production. Of note, the bacterial species measured in the study of Baldin et al. (2015) represented only a small fraction of the total rumen microbiome that can be potentially important to ruminal BH. Characterization of microbial population was beyond the scope of the current experiment.

A postrumen effect of methionine and analog compounds on milk fat synthesis has also been proposed (Patton et al., 1970; Huber et al., 1984; Zanton et al., 2014). Methionine plays an important role in choline synthesis, and methionine and choline both act as methyl donors, thereby potentially influencing milk volume and milk fat (Zanton et al., 2014). Additionally, methionine is involved in the transport of lipids (Patton et al., 1970) and its supplementation has been shown to increase blood triglycerides (Huber et al., 1984), which are a key substrate for milk fat synthesis. Contributions of postrumen effects to the milk fat response observed in the current study cannot be ruled out, but we expect that the rumen mechanism played the predominant role.

The experimental design used in our study verified the existence of interactions between dietary risk factors for MFD, animal characteristics, and a feed additive. Our approach provided an efficient way to investigate these interactions and demonstrated the potential of HMTBa to reduce BH-induced MFD. This important interaction could not have not been identified if the study had looked at a single factor at a time and should also represent on farm scenarios where gradual modifications in the diet increase the risk of BH-induced MFD.

\section{CONCLUSIONS}

High-producing cows had lower milk fat concentration than low-producing cows. During the treatment period, increasing diet UFA and carbohydrate fermentability caused MFD in high-producing cows receiving the control treatment, but HMTBa supplementation maintained higher milk fat concentration and yield, especially during the high-risk phase. Additionally, HMTBa maintained lower concentration of trans-10 C18:1 in milk; which suggested a role for HMTBa in stabilizing rumen $\mathrm{BH}$ and preventing the shift to the altered $\mathrm{BH}$ pathway. Low-producing cows neither experienced substantial $\mathrm{BH}$-induced MFD nor a response in milk fat to HMTBa supplementation. Characterization of the interaction of dietary risk factors, milk production level, and HMTBa supplementation provides a mechanism to prevent or attenuate $\mathrm{BH}$-induced MFD on farms and reduces its occurrence in high-producing cows within herds with normal milk fat. The experimental model offers a framework to further study other rumen modifiers that can combat BH-induced MFD.

\section{ACKNOWLEDGMENTS}

Gratitude is expressed to Y. Ying and N. Urrutia (Penn State University) for technical assistance and 
to the Pennsylvania State University Dairy Cattle Research and Education Center for continuous care of animals. We also thank Novus International and Penn State for support of the project.

\section{REFERENCES}

AOAC International. 2000. Official Methods of Analysis. 17th ed. AOAC International, Arlington, VA.

Bainbridge, M. L., L. M. Cersosimo, A.-D. G. Wright, and J. Kraft. 2016. Content and composition of branched-chain fatty acids in bovine milk are affected by lactation stage and breed of dairy cow. PLoS One 11:e0150386.

Baldin, M., Y. Ying, G. Zanton, H. Tucker, M. Vasquez-Anon, and K. Harvatine. 2015. 2-hydroxy-4-(methylthio) butanoate (hmtba) supplementation increases milk fat and decreases synthesis of alternative biohydrogenation intermediates in diets with risk for milk fat depression. J. Dairy Sci. 98(E-Suppl. 2):553. (Abstr.)

Ballou, M. A., R. Gomes, S. Juchem, and E. DePeters. 2009. Effects of dietary supplemental fish oil during the peripartum period on blood metabolites and hepatic fatty acid compositions and total triacylglycerol concentrations of multiparous Holstein cows. J. Dairy Sci. 92:6c57-669.

Bauman, D. E., and J. M. Griinari. 2003. Nutritional regulation of milk fat synthesis. Annu. Rev. Nutr. 23:203-227.

Chouinard, P. Y., L. Corneau, D. M. Barbano, L. E. Metzger, and D. E. Bauman. 1999. Conjugated linoleic acids alter milk fatty acid composition and inhibit milk fat secretion in dairy cows. J. Nutr. 129:1579-1584.

Hara, A., and N. S. Radin. 1978. Lipid extraction of tissues with a low-toxicity solvent. Anal. Biochem. 90:420-426.

Harvatine, K. J., and M. Allen. 2006. Effects of fatty acid supplements on milk yield and energy balance of lactating dairy cows. J. Dairy Sci. 89:1081-1091.

Harvatine, K. J., and D. Bauman. 2011. Characterization of the acute lactational response to trans-10, cis-12 conjugated linoleic acid. J. Dairy Sci. 94:6047-6056.

Harvatine, K. J., Y. Boisclair, and D. Bauman. 2009a. Recent advances in the regulation of milk fat synthesis. Animal 3:40-54.

Harvatine, K. J. 2017. Lipid and fat nutrition. Pages 655-666 in Large Dairy Herd Management, 3rd ed. D. Beede, ed. American Dairy Science Association, Champaign, IL.

Harvatine, K. J., and D. E. Bauman. 2006. Srebp1 and thyroid hormone responsive spot 14 (s14) are involved in the regulation of bovine mammary lipid synthesis during diet-induced milk fat depression and treatment with cla. J. Nutr. 136:2468-2474.

Harvatine, K. J., J. W. Perfield, and D. E. Bauman. 2009b. Expression of enzymes and key regulators of lipid synthesis is upregulated in adipose tissue during cla-induced milk fat depression in dairy cows. J. Nutr. 139:849-854.

Huber, T. J., R. Emery, W. Bergen, J. Liesman, L. Kung, K. King, R. Gardner, and M. Checketts. 1984. Influences of methionine hydroxy analog on milk and milk fat production, blood serum lipids, and plasma amino acids. J. Dairy Sci. 67:2525-2531.

Jenkins, T. C., R. Wallace, P. Moate, and E. Mosley. 2008. Boardinvited review: Recent advances in biohydrogenation of unsaturated fatty acids within the rumen microbial ecosystem. J. Anim. Sci. 86:397-412

Johnson-VanWieringen, L. M., J. Harrison, D. Davidson, M. Swift, M. Von Keyserlingk, M. Vazquez-Anon, D. Wright, and W. Chalupa. 2007. Effects of rumen-undegradable protein sources and supplemental 2-hydroxy-4-(methylthio)-butanoic acid and lysine. hcl on lactation performance in dairy cows. J. Dairy Sci. 90:5176-5188.

Koenig, K. M., L. Rode, C. Knight, and P. McCullough. 1999. Ruminal escape, gastrointestinal absorption, and response of serum methionine to supplementation of liquid methionine hydroxy analog in dairy cows. J. Dairy Sci. 82:355-361.
Lee, C., J. Oh, A. Hristov, K. Harvatine, M. Vazquez-Anon, and G. Zanton. 2015. Effect of 2-hydroxy-4-methylthio-butanoic acid on ruminal fermentation, bacterial distribution, digestibility, and performance of lactating dairy cows. J. Dairy Sci. 98:1234-1247.

Martin, C., C. Mirande, D. Morgavi, E. Forano, E. Devillard, and P. Mosoni. 2013. Methionine analogues hmb and hmbi increase the abundance of cellulolytic bacterial representatives in the rumen of cattle with no direct effects on fiber degradation. Anim. Feed Sci. Technol. 182:16-24.

Noftsger, S., N. St-Pierre, and J. Sylvester. 2005. Determination of rumen degradability and ruminal effects of three sources of methionine in lactating cows. J. Dairy Sci. 88:223-237.

Palmquist, D., and W. Mattos. 1978. Turnover of lipoproteins and transfer to milk fat of dietary (1-carbon-14) linoleic acid in lactating cows. J. Dairy Sci. 61:561-565.

Patton, R. A., R. McCarthy, and L. Griel. 1970. Observations on rumen fluid, blood serum, and milk lipids of cows fed methionine hydroxy analog 1, 2. J. Dairy Sci. 53:776-780.

Peel, C. J., T. J. Fronk, D. E. Bauman, and R. C. Gorewit. 1983. Effect of exogenous growth hormone in early and late lactation on lactational performance of dairy cows. J. Dairy Sci. 66:776-782.

Peterson, D. G., E. A. Matitashvili, and D. E. Bauman. 2003. Diet-induced milk fat depression in dairy cows results in increased trans-10,cis-12 cla in milk fat and coordinate suppression of mrna abundance for mammary enzymes involved in milk fat synthesis. J. Nutr. 133:3098-3102.

Rico, D. E., A. Holloway, and K. Harvatine. 2014a. Effect of monensin on recovery from diet-induced milk fat depression. J. Dairy Sci. 97:2376-2386.

Rico, D. E., S. Preston, J. Risser, and K. Harvatine. 2015. Rapid changes in key ruminal microbial populations during the induction of and recovery from diet-induced milk fat depression in dairy cows. Br. J. Nutr. 114:358-367.

Rico, D. E., Y. Ying, and K. Harvatine. 2014b. Effect of a high-palmitic acid fat supplement on milk production and apparent total-tract digestibility in high-and low-milk yield dairy cows. J. Dairy Sci. 97:3739-3751.

Rico, D. E., and K. J. Harvatine. 2013. Induction of and recovery from milk fat depression occurs progressively in dairy cows switched between diets that differ in fiber and oil concentration. J. Dairy Sci. 96:6621-6630.

Rosser, R., C. Polan, P. Chandler, and T. Bibb. 1971. Effects of whey components and methionine analog on bovine milk fat production. J. Dairy Sci. 54:1807-1816.

Shingfield, K., and R. Wallace. 2014. Synthesis of conjugated linoleic acid in ruminants and humans. Pages 1-65 in Conjugated Linoleic Acids and Conjugated Vegetable Oils. B. Sels and A. Philippaerts, ed. Royal Society of Chemistry, London, UK.

Sukhija, P. S., and D. Palmquist. 1988. Rapid method for determination of total fatty acid content and composition of feedstuffs and feces. J. Agric. Food Chem. 36:1202-1206.

Van Soest, P. J., J. Robertson, and B. Lewis. 1991. Methods for dietary fiber, neutral detergent fiber, and nonstarch polysaccharides in relation to animal nutrition. J. Dairy Sci. 74:3583-3597.

Vázquez-Añón, M., T. Cassidy, P. McCullough, and G. Varga. 2001. Effects of alimet on nutrient digestibility, bacterial protein synthesis, and ruminal disappearance during continuous culture. J. Dairy Sci. 84:159-166.

Zanton, G. I., G. Bowman, M. Vázquez-Añón, and L. Rode. 2014 Meta-analysis of lactation performance in dairy cows receiving supplemental dietary methionine sources or postruminal infusion of methionine. J. Dairy Sci. 97:7085-7101.

Zebeli, Q., M. Tafaj, I. Weber, J. Dijkstra, H. Steingass, and W. Drochner. 2007. Effects of varying dietary forage particle size in two concentrate levels on chewing activity, ruminal mat characteristics and passage in dairy cows. J. Dairy Sci. 90:1929-1942. 